\title{
Assessment of grief in mothers with pregnancy loss and role of post bereavement counselling: a prospective study
}

\author{
Jaishree Surendrakumar Bamniya*, Gopal Omprakash Bhatia, \\ Haresh Umedchand Doshi, Harshad Manilal Ladola,
}

Department of Obstetrics and Gynecology, GCS Medical College, Ahmedabad, Gujarat, India

Received: 18 February 2018

Accepted: 28 February 2018

\section{*Correspondence:}

Dr. Jaishree Surendrakumar Bamniya,

E-mail: sh1311@yahoo.in

Copyright: ( $)$ the author(s), publisher and licensee Medip Academy. This is an open-access article distributed under the terms of the Creative Commons Attribution Non-Commercial License, which permits unrestricted non-commercial use, distribution, and reproduction in any medium, provided the original work is properly cited.

\begin{abstract}
Background: Pregnancy is usually a joyful experience for a woman. It is one of the milestones that, even though sometimes stressful, is rewarding for the reason that the woman takes on a new level of responsibility. Objective of present study was to assess the psychological problems associated with Pregnancy loss and effectiveness of post bereavement counselling in subjects with perinatal grief.

Methods: This was a prospective study. This study was conducted at Obstetrics and Gynecology Department of GCS Medical College and Hospital from January 2013 to June 2016 in collaboration with Psychiatrist of evaluation of subjects. A total of 404 patients were taken in the study. All patients with pregnancy loss including abortions, ectopic pregnancy, Intrauterine death, Stillbirth and neonatal deaths who consented to be a part of study were included in the study. After taking informed consent, study participants were assessed for perinatal grief by Perinatal Grief scale 33(PGS-33).

Results: Results indicate that the process of active grief begins to occur soon after loss and resolves itself over time if no complicating factors are present. Time was found to interact with other factors in the grieving process. The number of perinatal losses, time, and the presence of living children were related to the difficulty with coping subscale of the PGS-S.

Conclusions: Though time is the best healer, intervention in the form of counselling can be beneficial for patients with difficult coping and despair. Our experience with PGS-33 was that it is not very user friendly especially for patients with low education status. So, changes should be made to further simply such scales so it can be used widely and assessment should be simplified.
\end{abstract}

Keywords: Depression, IUD, NND, Perinatal grief, PIH, PGS-33, Still birth

\section{INTRODUCTION}

Pregnancy is usually a joyful experience for a woman. It is one of the milestones that, even though sometimes stressful, is rewarding for the reason that the woman takes on a new level of responsibility. Parents look forward to delivering a healthy baby and dream of a happy and contented future. Such plans and dreams are shattered when the death of an unborn or newborn infant occurs. Pregnancy loss is a painful and traumatic event that can occur at any time during the pregnancy. ${ }^{1}$

Perinatal losses have also been shown to have a substantial psychological impact on parents and families, and are associated with post-traumatic stress, depression, anxiety, and sleeping disorders., ${ }^{2,3}$

Although parents have not built up a relationship with their infant, grief after pregnancy loss does not differ 
significantly in intensity from other loss scenarios. As has been found in bereavement involving first-degree relatives, grief symptoms usually decrease in intensity over the first 12 months. Longitudinal studies have demonstrated that in a normal grieving process, grief declines over a period of 2 years after the pregnancy loss. ${ }^{4,5}$

The specific aims and objectives of the study were

- To find out etiological factors leading to pregnancy loss.

- To find out Stillbirth rate, PNM rate at our institution.

- To find out incidence of psychological problems like depression, anxiety, anger and worry of outcome of future pregnancy.

- To assess the psychological problems before and after standard care and bereavement counselling for women with pregnancy loss.

- To validate the perinatal bereavement grief scale for the local population

- To assess the effectiveness of bereavement counselling on women with pregnancy loss

\section{METHODS}

After obtaining permission from Institutional ethical and scientific committee, study was conducted from year Jan 2013 to June 2016 at Obstetrics and Gynecology Department in collaboration with Psychiatry department of GCS Medical college and Research centre, Ahmedabad.

All patients with pregnancy loss including abortions, ectopic pregnancy, Intrauterine death, Stillbirth and neonatal deaths who consented to be a part of study were included in the study. After taking informed consent, study participants were assessed for perinatal grief by Perinatal Grief scale-33(PGS-33).

The Perinatal Grief Scale is a questionnaire that has been successfully used to quantitatively measure active grief, difficulty with coping, and despair (Potvin, Lasker, Toedter, 1989).

The PGS examined three aspects of grieving: active grief, difficulty coping, and despair. Examination of these categories in relation to the length of time that had passed since the loss led to greater insight into the psychological ramifications of miscarriage and termination for fetal abnormality. Active grief addresses sadness and missing or crying for the baby. As the most positive form of grief, it leads to less psychological difficulties.

Difficulty coping is evidenced in difficulties with both daily activities and interactions with other people. This is an indicator of more severe depressive symptomalogy because individuals scoring high on this scale withdraw from others and have trouble functioning on a daily level.
The despair subscale is a predictor of serious and longlasting negative psychological effects. Each patient filled two questionnaire, one was within first week of the loss and other was 6 weeks after the loss. Irrespective of grief score all patients were subjected to counselling.

\section{RESULTS}

The study spanned over a period of two years and six monthes from January 2013 to June 2016. A total of 2568 patient delivered in Obstetric Unit of GCS Hospital and Medical college. We included all subjects who had stillbirth, intrauterine deaths, neonatal death, abortion and ectopic in present study. A total of 404 subjects were included in the study group. After taking informed consent, study participants were assessed for perinatal grief by Perinatal Grief scale -33(PGS-33). The Perinatal Grief Scale is a questionnaire that has been successfully used to quantitatively measure active grief, difficulty with coping, and despair (Potvin, Lasker, and Toedter, 1989). The PGS examined three aspects of grieving: active grief, difficulty coping, and despair.

Table 1: Distribution of patients according to number of deliveries.

\begin{tabular}{|lllllll|}
\hline Year & $\begin{array}{l}\text { Total } \\
\text { deliveries }\end{array}$ & IUD & SB & NND & A & E \\
\hline 2013 & 708 & 19 & 1 & 4 & 108 & 10 \\
\hline 2014 & 820 & 15 & 5 & 10 & 78 & 2 \\
\hline 2015 & 1361 & 6 & 3 & 12 & 68 & 8 \\
\hline 2016 & 679 & 2 & 4 & 6 & 37 & 6 \\
\hline Total & 2568 & 42 & 13 & 32 & 291 & 26 \\
\hline
\end{tabular}

Out of total deliveries at our institute from January 2013 to June 2016 i.e. 2568. Intrauterine deaths comprised $1.635 \%$, stillbirth $(0.5 \%)$, neonatal death $(1.24 \%)$, abortion $(11.33 \%)$ and ectopic $(4.41 \%)$ (Table 1$)$.

Table 2: Distribution of patients according to age, education, parity.

\begin{tabular}{|lll|l|}
\hline Age & $20-30$ & $30-40$ & $>40$ \\
\hline \multirow{2}{*}{ Education } & 340 & 61 & 3 \\
\hline & Illiterate & $\begin{array}{l}\text { Upto } \\
\text { secondary }\end{array}$ & Graduate \\
\hline Parity & 44 & 280 & 124 \\
\hline & Nullipara & Para1 & Para2/More \\
\hline & 48 & 196 & 160 \\
\hline
\end{tabular}

Distribution of patients according to age, education and parity showed that maximum subjects were in the age group of 20-30 years (84\%) followed by age group 30-40 constituting around $15 \%$ and $>40$ with $0.7 \%$ contribution. In Education level $69.30 \%$ subjects were educated upto secondary followed by Graduates (30\%) and illiterates (10.89\%). According to Parity $48.51 \%$ subjects were Para 1 followed by Para2 (39.60\%) and nullipara (11.88\%) (Table 2). 
Table 3: Classification of types of pregnancy loss.

\begin{tabular}{|ll|l|}
\hline & $\mathrm{N}=404$ & $\%$ \\
\hline Miscarriage & 291 & 72.02 \\
\hline Ectopic & 26 & 6.43 \\
\hline Intrauterine death & 42 & 10.39 \\
\hline Stillbirth & 13 & 3.21 \\
\hline Neonatal death & 32 & 7.92 \\
\hline
\end{tabular}

According to type of pregnancy loss Miscarriages had Maximum contribution of $72.02 \%$ followed by IUD (10.39\%), NND (7.92\%), ectopic (6.43\%) and lastly stillbirth $(3.21 \%)$ (Table 3$)$.

Table 4: Etiological factors for late pregnancy loss.

\begin{tabular}{|l|l|}
\hline Etiological factors & \\
\hline Multiple pregnancy & 5 \\
\hline Preterm & 24 \\
\hline Low birth weight & 30 \\
\hline Chromosomal anomalies & 1 \\
\hline Birth asphyxia & 33 \\
\hline Severe IUGR & 30 \\
\hline PIH & 36 \\
\hline Antepartum haemorrhage & 16 \\
\hline Oligohydramnios & 24 \\
\hline Cord abnormalities & 4 \\
\hline Maternal diabetes & 4 \\
\hline Congenital anomalies & 2 \\
\hline Rupture uterus & 1 \\
\hline
\end{tabular}

According to etiology of late fetal loss pregnancy induced hypertension is the most common cause of fetal loss followed by birth asphyxia, severe IUGR, low birth weight, preterm, oligohydramnios. In many cases factors were coexisting like pregnancy induced hypertension leading to severe IUGR or abruption (Table 4).

Table 5: Distribution of subjects according to precounselling score on PGS.

\begin{tabular}{|lll|}
\hline & $\mathrm{N}=\mathbf{4 0 4}$ & $\%$ \\
\hline Active grief & 380 & 94.05 \\
\hline Difficulty coping & 19 & 4.7 \\
\hline Despair & 5 & 1.2 \\
\hline
\end{tabular}

Distribution of subjects according to pre-counselling score around $94.05 \%$ subjects were in active grief followed by difficult coping (4.7\%) and only $1.2 \%$ subjects were in despair. Active grief addresses sadness and missing or crying for the baby.

As the most positive form of grief, it leads to less psychological difficulties. Difficulty coping is evidenced in difficulties with both daily activities and interactions with other people. This is an indicator of more severe depressive symptomalogy because individuals scoring high on this scale withdraw from others and have trouble functioning on a daily level. The despair subscale is a predictor of serious and long-lasting negative psychological effects (Table 5).

Table 6: Distribution of subjects according to postcounselling score on PGS.

\begin{tabular}{|lll|}
\hline & N & $\%$ \\
\hline Active grief & 398 & 98.51 \\
\hline Difficulty coping & 4 & 0.99 \\
\hline Despair & 2 & 0.49 \\
\hline
\end{tabular}

Distribution of subjects according to Post-counselling score around $98.51 \%$ subjects were in Active Grief followed by Difficult Coping (0.99\%) and only $0.49 \%$ subjects were in Despair. This observation shows that counselling had a positive impact on the subjects leading to reduction in percentage of subjects who showed Difficult coping from $4.7 \%$ in Pre-counselling period to $0.99 \%$ in Post-counselling period while subjects who showed signs of Despair i.e. $1.2 \%$ declined to $0.49 \%$ (Table 6).

\section{DISCUSSION}

Every year, there are over 6.3 million perinatal deaths in the world, of which almost all occur in the developing countries, and $27 \%$ of them occur in the least developed countries. ${ }^{6}$ Research shows that psychiatric morbidity following perinatal death varies from $13 \%$ to $34 \%$ among mothers suffering from perinatal bereavement. ${ }^{7}$

Twenty-five to $40 \%$ of the couples experiencing perinatal loss report anxiety or depressive symptoms soon after the loss or in the subsequent two years. ${ }^{8}$ Women may experience psychological problems such as grief, depression, and anxiety. ${ }^{9}$ Some health personnel may not be aware of the extent to which these problems are manifested. ${ }^{10}$

Identifying psychological problems and providing counselling to such women is much needed to address their fear of problems in future pregnancies and family life. An intervention cannot bring back their beloved infant, but an appropriate intervention could promote physical and emotional healing. Routine intervention for bereavement has not received support from quantitative evaluations of its effectiveness and is therefore not empirically based. Outreach strategies are not advised, and even provision of intervention for those who believe that they need it and who request it should be carefully evaluated. Intervention soon after bereavement may interfere with "natural" grieving processes. Intervention is more effective for those with more complicated forms of grief. ${ }^{11}$ The amount of time that had passed since the most recent loss was significantly related to the PGS scores.

The length of the pregnancy indicates that the longer the woman is pregnant, the more time she has to bond with the unborn child. This results in a greater degree of grief. 
Women who experienced a longer pregnancy had more sadness, guilt, anger, and preoccupation with the loss. The acuity of grief lessens over time. The subscale of the PGS-S influenced significantly by time was active grieving. This measures grief as evidenced by sadness, and missing or crying for the baby. Results indicate that the process of active grief begins to occur soon after loss and resolves itself over time if no complicating factors are present. Time was found to interact with other factors in the grieving process. The number of perinatal losses, time, and the presence of living children were related to the difficulty with coping subscale of the PGS-S. Women whose loss had occurred closer to the time when they filled out the questionnaire, had greater numbers of perinatal losses, and no living children experienced greater difficulties. Evidence of difficulties were reflected in accomplishing daily activities and dealing with other people. They may be withdrawing from others and having trouble functioning on a daily level.

Counselling, as reported by respondents, was found to help with thoughts and feelings regarding sadness, guilt, anger, and preoccupation with the loss. The intervention of counselling was significantly related to the active grief subscale. Thus, counselling facilitates the process of grief work, and leads to less psychological difficulties. Women who get some form of counselling may be better able to process the loss and experience less severe grief symptomalogy.

\section{CONCLUSION}

Though time is the best healer, intervention in the form of counselling can be beneficial for patients with difficult coping and despair. Our experience with PGS-33 was that it is not very user friendly especially for patients with low education status. So, changes should be made to further simply such scales, so it can be used widely and assessment should be simplified.

Funding: No funding sources Conflict of interest: None declared

Ethical approval: The study was approved by the Institutional Ethics Committee

\section{REFERENCES}

1. Simpson C, Lee P, Lione J. The effect of bereavement counseling on women with psychological problems associated with late pregnancy loss. J Asian Midwives. 2015;2(2):

2. Hughes P, Riches S. Psychological aspects of perinatal loss. Curr Opin Obstet Gynecol. 2003;15:107-11.

3. Boyle FM, Vance JC, Najman JM, Thearle MJ. The mental health impact of stillbirth, neonatal death or SIDS: prevalence and patterns of distress among mothers. Soc Sci Med. 1996;43:1273-82.

4. Janssen HJ, Cuisinier MC, de Graauw KP, Hoogduin KA. A prospective study of risk factors predicting grief intensity following pregnancy loss. Arch Gen Psychiatry. 1997;54:56-61.

5. Lasker JN, Toedter LJ. Acute versus chronic grief: the case of pregnancy loss. Ami J Orthopsychiatry. 1991;61:510-22.

6. World Health Organization. Neonatal and Perinatal mortality - Country, Regional and Global Estimates Mortality. 2007.

7. Kirkley-Best E, Kellner KR. The forgotten grief a review of the psychology of stillbirth. Am J Orthopsych. $1982 ; 52(3): 420-9$.

8. Lin SX, Lasker JN. Patterns of grief reaction after pregnancy loss. Am J Orthopsychiatry. 1996;66:262.

9. Bennett SM, Litz B T, Sarnoff Lee B, Maguen S. The scope and impact of perinatal loss Current status and future directions. Profession Psychol Res Practice. 2005;36:180-7.

10. Sutan R, Miskam HM. Psychosocial impact of perinatal loss among Muslim women. BMC Women's Health. 2012;18:12.

11. Schut H, Stroebe MS. Interventions to enhance adaptation to bereavement. J Palliat Med. 2005;8Suppl 1:S140-7.

Cite this article as: Bamniya JS, Bhatia GO, Doshi HU, Ladola HM. Assessment of grief in mothers with pregnancy loss and role of post bereavement counselling: a prospective study. Int J Reprod Contracept Obstet Gynecol 2018;7:1347-50. 